\title{
Transient Plasticity of Hippocampal CAI Neuron Glutamate Receptors Contributes to Benzodiazepine Withdrawal-Anxiety
}

\author{
Bradley J Van Sickle', Kun Xiang' and Elizabeth I Tietz*,I \\ 'Department of Pharmacology and the Cellular and Molecular Neurobiology Program, Medical College of Ohio, Toledo, OH, USA
}

\begin{abstract}
Withdrawal from I-week oral administration of the benzodiazepine (BZ), flurazepam (FZP) is associated with enhanced AMPA receptor (AMPAR)-mediated and reduced NMDA receptor (NMDAR)-mediated excitation in CAI pyramidal neurons 2-days after cessation of FZP administration. The present study examined temporal regulation of glutamate receptor-mediated whole-cell currents in CAI neurons from hippocampal slices prepared from 0-, I-, 2-, and 4-day FZP-withdrawn rats in relation to expression of anxiety-like behavior during BZ withdrawal. AMPAR-mediated miniature excitatory postsynaptic current (mEPSC) amplitude was significantly increased in CAI neurons from I- and 2-day FZP-withdrawn rats, while evoked NMDAR EPSC amplitude was reduced only in neurons from 2-day FZP-withdrawn rats. Withdrawal-anxiety, measured in the elevated plus-maze, was observed I day, but not 0 , 2, or 4 days, after FZP treatment with I-day withdrawn rats spending significantly reduced time in open arms compared to controls CAI neuron hyperexcitability was evident from the significant increase in the frequency of extracellular, 4-AP-induced spike discharges in slices from I-day FZP-withdrawn rats. Systemic injection of the NMDAR antagonist MK-80I (0.25 mg/kg) on day I of withdrawal prevented reduced NMDAR-mediated currents in CAI neurons from 2-day FZP-withdrawn rats, whereas AMPAR-mediated currents remained upregulated. Furthermore, MK-80I 'unmasked' withdrawal-anxiety in the same 2-day FZP-withdrawn rats. Systemic injection of the AMPAR antagonist GYKI-52466 $(0.5 \mathrm{mg} / \mathrm{kg})$ at the onset of withdrawal blocked increased AMPAR-mediated currents and withdrawal-anxiety in I-day FZP-withdrawn rats. These findings suggest that increased CAI neuron AMPAR-mediated excitation may contribute to hippocampal hyperexcitability and expression of withdrawal-anxiety after prolonged BZ exposure via NMDAR-mediated neural circuits.

Neuropsychopharmacology (2004) 29, 1994-2006, advance online publication, 2 I July 2004; doi: I 0.1038/sj.npp. I 30053 I
\end{abstract}

Keywords: AMPA, NMDA, hippocampus, anxiety, tolerance, drug abuse

\section{INTRODUCTION}

Recent molecular approaches have established that the distinct clinical effects of benzodiazepines (BZs) are mediated by the contributions of different $\mathrm{GABA}_{\mathrm{A}}$ receptor (GABAR) $\alpha$ subunits to $\mathrm{BZ}$ allosteric binding sites on the GABAR. BZ anticonvulsant and hypnotic actions are likely mediated by $\alpha 1$ subunit-containing GABARs and their anxiolytic actions by $\alpha 2$ subunit-containing GABARs, in particular in cortex and hippocampus (Mohler et al, 2002). Despite their potent actions, the clinical utility of BZs can be limited by tolerance, especially to their anticonvulsant actions, and by the emergence of a withdrawal syndrome

\footnotetext{
*Correspondence: Dr El Tietz, Department of Pharmacology, Medical College of Ohio, 3035 Arlington Ave. Toledo, OH 436I4, USA, Tel: + I 419383 4170, Fax: + I 419383 287I, E-mail: etietz@mco.edu Received II May 2004; revised 18 June 2004; accepted 2 I June 2004 Online publication: 23 June 2004 at http://www.acnp.org/citations/ Npp06230404219/default.pdf
}

following rapid discontinuation of prolonged BZ therapy. Withdrawal symptoms range from mild to severe and may include anxiety, insomnia, muscle spasms, and seizures. Many BZ users and abusers continue to use BZs to avoid withdrawal symptoms. Thus, a typical drug-dependence syndrome may underlie misuse of BZs among patients undergoing treatment, as well as contribute to their recreational abuse (Griffiths and Weerts, 1997).

The role of plasticity within excitatory glutamatergic neuronal circuits in mediating various aspects of drug addiction has recently been an area of intense investigation (reviewed in: Berke and Hyman, 2000; Carlezon and Nestler, 2002; Nestler, 2001a). Glutamate receptors have been broadly implicated in withdrawal phenomena associated with a variety of drugs of abuse (Jackson et al, 2000; Little, 1999; Trujillo and Akil, 1995). After chronic opioid treatments, $\mathrm{N}$-methyl-D-aspartate receptor (NMDAR) antagonists block the development of withdrawal signs (reviewed in Trujillo and Akil, 1995), while antagonists of $\alpha$-amino-3-hydroxy-5-methyl-4-isozaxolepropionic acid 
receptors (AMPARs) reduce expression of withdrawal behaviors (reviewed in Jackson et al, 2000). Moreover, increased CA1 neuron AMPAR-mediated excitatory postsynaptic potentials correlate with withdrawal hyperexcitability following chronic ethanol (Molleman and Little, 1995), and NMDAR binding and subunit expression in hippocampus are regulated in pentobarbital-withdrawn rats (Jang et al, 1998; Oh et al, 1997). The observations that pharmacologic antagonism of AMPARs and NMDARs modifies behavioral manifestations of BZ withdrawal (Steppuhn and Turski, 1993; Tsuda et al, 1998) and that AMPAR binding increases in the hippocampus and frontal cortex following withdrawal from diazepam (Allison et al, 1999) provide evidence that glutamate receptors are also important in BZ withdrawal. Nevertheless, the neural mechanisms fundamental to the expression of $\mathrm{BZ}$ withdrawal remain to be clearly identified.

Recent studies from our laboratory demonstrated that AMPAR-mediated currents were selectively enhanced and NMDAR-mediated currents were concurrently reduced in hippocampal CA1 pyramidal, but not dentate granule (DG), neurons from 2-day flurazepam (FZP)-withdrawn rats. Moreover, these changes correlated with localized increases in AMPAR-antagonist binding and decreases in NR2B subunit mRNA and protein levels in the CA1, but not CA3 or DG, region, the latter observation consistent with a decreased efficacy of NMDA applied to isolated CA1 neurons (Van Sickle and Tietz, 2002; Van Sickle et al, 2002). Modulation of hippocampal glutamatergic function may be important in BZ withdrawal behaviors, as the hippocampus is an integral component of several neural circuits implicated in the expression of anxiety (Andrews et al, 1997; File et al, 1996; McNaughton and Gray, 2000; Menard and Treit, 2001; Millan, 2003) and seizures can originate in the hippocampus during BZ withdrawal (Steppuhn and Turski, 1993). In support of this possibility, Izzo et al (2001) demonstrated increased AMPAR subunit GluR1 protein in rat hippocampus, which corresponded with anxiety-like behavior in an elevated plus-maze during withdrawal from chronic diazepam. Here, we investigated whether the functional regulation of glutamate receptors on CA1 neurons after prolonged BZ administration may be a neurophysiological component for expression BZ withdrawal-anxiety.

Accordingly, the temporal pattern of changes in AMPAR and NMDAR-mediated whole-cell currents in rat hippocampal CA1 pyramidal neurons was evaluated in the context of BZ withdrawal-anxiety measured in the elevated plus-maze in the same rats. Extracellular recordings of 4-aminopyridine (4-AP)-induced CA1 neuron spike discharges examined the possible effects of endogenous glutamate release on AMPAR regulation of hippocampal excitability. Acute pharmacological antagonism of AMPARs and NMDARs during FZP withdrawal assessed the functional role of both excitatory receptor types in the expression of withdrawal-induced anxiety. The findings strongly support a neurophysiological mechanism by which localized enhancement of AMPAR-mediated excitability in hippocampal CA1 neurons contributes to behavioral expression of $\mathrm{BZ}$ withdrawal-anxiety through brain anxiety circuits that require an intact NMDAR functional pathway within the hippocampus.

\section{MATERIALS AND METHODS}

Experimental protocols involving the use of vertebrate animals were approved by the Medical College of Ohio, Institutional Animal Care and Use Committee (IACUC) and conformed to National Institutes of Health guidelines.

\section{Drug Treatments}

As previously described (Van Sickle et al, 2002), male Sprague-Dawley rats (Harlan, Indianapolis, IN) were adapted to a $0.02 \%$. saccharin water vehicle, then offered the water-soluble BZ, flurazepam (FZP dihydrochloride, $\mathrm{pH}$ 5.8) for 1 week ( $100 \mathrm{mg} / \mathrm{kg}$ for 3 days, $150 \mathrm{mg} / \mathrm{kg}$ for 4 days) in their drinking water. Daily water consumption was monitored for each rat and used to adjust drug concentration so that the criterion dose ( $>120 \mathrm{mg} / \mathrm{kg} /$ day) of FZP was achieved. Matched control rats received only saccharin water. At the end of drug administration, rats were offered saccharin water during FZP withdrawal for $0,1,2$, or 4 days prior to behavioral testing and/or hippocampal slice preparation on P35-45 (150-180 g, final weight). Unlike in humans, residual FZP and metabolites rapidly decline over the first $24 \mathrm{~h}$ after drug removal and are no longer detectable in hippocampus in 2-day FZP-withdrawn rats (Xie and Tietz, 1992).

To evaluate the effect of acute BZ treatment on withdrawal-anxiety or GABAR-mediated inhibition, rats were given a single gavage of the primary FZP active metabolite, desalkyl-FZP $(2.5 \mathrm{mg} / \mathrm{kg}), 1$ day before behavioral testing and/or hippocampal slice preparation. Food was removed $12 \mathrm{~h}$ prior to gavage. Control rats received an equivalent volume of emulsion vehicle (peanut oil, water and acacia $(4: 2: 1))$. This acute desalkyl-FZP treatment was demonstrated to result in brain levels of residual BZ metabolite activity equivalent to that found in the hippocampus of rats after 1-week FZP treatment without effect on CA1 neuron inhibitory (Xie and Tietz, 1992) or excitatory function (Van Sickle and Tietz, 2002; Van Sickle et al, 2002).

Additional groups of FZP-withdrawn and control rats used for behavioral testing and subsequent electrophysiological recording were given a single glutamate receptor antagonist treatment by intraperitoneal injection. Rats received the noncompetitive NMDAR antagonist, MK-801 $(0.25 \mathrm{mg} / \mathrm{kg})$, or saline vehicle $(1 \mathrm{ml} / \mathrm{kg})$ or the selective, noncompetitive AMPAR antagonist, GYKI-52466 (0.5 or $5 \mathrm{mg} / \mathrm{kg}$; Tarnawa and Vize, 1998), or $1 \%$ TWEEN-20 vehicle $(0.5 \mathrm{ml} / \mathrm{kg})$. Systemic injections were made at timepoints as described in the text and were $24 \mathrm{~h}$ prior to behavioral testing and hippocampal slice preparation. The dose of MK-801 was based on its effect to block tolerance to diazepam's sedative effects (File and Fernandes, 1994). Since this dose had the predicted effect in FZP-withdrawn rats without adverse effects in control rats, additional doses were not evaluated. The initial treatment dose of GYKI-52466 chosen $(5 \mathrm{mg} / \mathrm{kg})$ was shown to inhibit acquisition of conditioned place preference by diazepam (Gray et al, 1999). Although this dose prevented AMPAR upregulation (data not shown), preliminary behavioral studies suggested a modest anxiogenic effect in control rats. Therefore, a dose one log-unit lower $(0.5 \mathrm{mg} / \mathrm{kg})$ was subsequently used. 


\section{Electrophysiology}

Hippocampal slice preparation. Hippocampal slices $(450 \mu \mathrm{m})$ were prepared from FZP-withdrawn and control rats as described (Van Sickle and Tietz, 2002). Rats were decapitated and transverse hippocampal slices prepared on a vibratome (Ted Pella, Inc., Redding, CA) in ice-cold, pregassed $\left(95 \% \mathrm{O}_{2} / 5 \% \mathrm{CO}_{2}\right)$ ACSF containing (in $\mathrm{mM}$ ): $\mathrm{NaCl}, 120 ; \mathrm{KCl}, 2.5 ; \mathrm{CaCl}_{2}, 0.5 ; \mathrm{MgSO}_{4}, 7.0 ; \mathrm{NaH}_{2} \mathrm{PO}_{4}, 1.2$; $\mathrm{NaHCO}_{3}$, 2; D-glucose, 20; ascorbate, 1.3; pH 7.4. Slices were maintained at room temperature for $\sim 15 \mathrm{~min}$ in gassed, low- $\mathrm{Ca}^{2+}$, high- $\mathrm{Mg}^{2+}$ ACSF, then transferred to normal ACSF ( NaCl, $119 ; \mathrm{KCl}, 2.5 ; \mathrm{CaCl}_{2}, 1.8 ; \mathrm{MgSO}_{4}, 1.0 ; \mathrm{NaH}_{2} \mathrm{PO}_{4}$, 1.25; $\mathrm{NaHCO}_{3}, 26$; D-glucose, $10 ; \mathrm{pH}$ 7.4) for $\geqslant 1 \mathrm{~h}$. During recording, slices were perfused at $2.5 \mathrm{ml} / \mathrm{min}$ with gassed normal ACSF at room temperature.

Whole-cell recording of excitatory responses. AMPARmediated, action potential-independent, miniature excitatory postsynaptic currents (mEPSCs) were isolated from CA1 pyramidal neurons in the presence of $1 \mu \mathrm{M}$ TTX, $10 \mu \mathrm{M}$ glycine, $25 \mu \mathrm{M}$ CGP-35348 and $50 \mu \mathrm{M}$ picrotoxin using whole-cell voltage-clamp techniques. These events can be abolished by DNQX $(10 \mu \mathrm{M})$ and are unaffected by APV $(50 \mu \mathrm{M}$; Van Sickle and Tietz, 2002). Patch pipettes (5-9 M 2 ) were filled with internal solution containing (in $\mathrm{mM}$ ): Cs-methanesulfonate, 132.5 ; $\mathrm{CsCl}, 17.5$; HEPES, 10; EGTA, 0.2; NaCl, 8; Mg-ATP, 2; $\mathrm{Na}_{3}$-GTP, 0.3; QX-314, 2; pH 7.2 adjusted with CsOH. Resting membrane potential (RMP) was measured immediately upon cell break-in. Neurons were voltage-clamped $\left(V_{\mathrm{H}}=-80 \mathrm{mV}\right)$ in continuous mode (cSEVC) using an Axoclamp 2A amplifier (Axon Instruments Inc., Foster City, CA). Current output was low-pass filtered $(10 \mathrm{kHz})$, DC-offset, amplified 10000 -fold and continuously monitored on-line (PClamp 6.0 Software, Axon Instruments Inc.). The digitized (Digidata 1200, Axon) signal was stored on disk for later off-line analysis. Cells in which the holding current changed by more than $20 \%$ or the seal degraded were abandoned. Baseline mEPSC activity was recorded in each neuron for at least $5 \mathrm{~min}$. Recorded events were detected and averaged using MiniAnalysis software (Synaptosoft Inc., Leonia, NJ). Peak mEPSC amplitude was measured from baseline. Decay kinetics and mEPSC amplitude were also estimated using a single exponential function: $[y(t)=a$ $\exp (-t / \tau)]$

Stimulus-evoked, NMDAR-mediated EPSCs were recorded from CA1 pyramidal neurons in rat hippocampal slices by stimulation of the Schaffer collateral pathway in the presence of $10 \mu \mathrm{M}$ DNQX, $10 \mu \mathrm{M}$ glycine, $25 \mu \mathrm{M}$ CGP-35348 and $50 \mu \mathrm{M}$ picrotoxin. As reported previously, evoked currents could be abolished by omission of glycine or the presence of $50 \mu \mathrm{M}$ APV (Van Sickle et al, 2002). Area CA3 was removed during slice preparation to prevent recurrent activation and epileptiform discharges during electrical stimulation in the presence of GABAR antagonists. Neurons were voltage-clamped from -80 to $+40 \mathrm{mV}$ in cSEVC. NMDAR-mediated EPSCs were elicited by tungsten, bipolar stimulating electrode at an intensity $(\sim 0.1-0.8 \mathrm{~mA})$ half-maximal for the eEPSC. Current output was recorded as described above and analyzed using PClamp 6.0 (Axon).
Extracellular recording of spike discharges. CA1 neuron excitability was measured using extracellular recording techniques in hippocampal slices from 1-day FZP-withdrawn rats. Excitability was measured by the ability of 4aminopyridine (4-AP) to induce glutamate release and thus spike discharges in the CA1 pyramidal cell region (Salazar et al, 2003). Extracellular recordings were made with $2 \mathrm{M}$ $\mathrm{NaCl}$-filled electrodes $(2-4 \mathrm{M} \Omega)$ placed in stratum pyramidale of the CA1 region. Discharges were amplified (DAM80, World Precision Instr., Sarasota, FL) 1000-fold and filtered $(3 \mathrm{kHz}, 10 \mathrm{~Hz})$. Signals were acquired continuously online (PClamp 6.0 Software) during 5 min baseline superfusion of ACSF followed by 40 min superfusion of $55 \mu \mathrm{M} 4$ AP. The offset of drug effect was monitored during $15 \mathrm{~min}$ drug washout with ACSF superfusion. The frequency of spikes per $5 \mathrm{~min}$ epoch was counted using MiniAnalysis software and plotted as a function of time.

Whole-cell recording of inhibitory responses. To assess the status of GABAR-mediated inhibition at the time when anxiety was present, GABAR-mediated miniature inhibitory postsynaptic currents (mIPSCs) were recorded in symmetrical $\mathrm{Cl}^{-}$solutions in hippocampal slices from 1-day FZPwithdrawn rats in which AMPA or NMDA responses were also recorded. As detailed previously (Tietz et al, 1999; Zeng and Tietz, 1999), patch pipettes for mIPSC recording were filled with (in mM): CsCl, 130; HEPES, 10; EGTA, 1; $\mathrm{CaCl}_{2}$, $0.5 ; \mathrm{MgCl}_{2}, 2$; Mg-ATP, 2; QX-314, 2; pH 7.2 adjusted with $\mathrm{CsOH}$. Slices were superfused with $1 \mu \mathrm{M}$ TTX, $50 \mu \mathrm{M}$ APV, $10 \mu \mathrm{M}$ DNQX and $25 \mu \mathrm{M}$ CGP-35348. To assess residual BZ effects 1-day after FZP treatment, mIPSCs were also recorded before and after $10 \mathrm{~min}$ superfusion of the $\mathrm{BZ}$ antagonist, flumazenil $(1 \mu \mathrm{M})$. GABAR mIPSCs were recorded for 2 min before and after 10 min drug application, then detected and analyzed as described above.

\section{Behavioral Testing}

The elevated plus-maze (open arms: $50 \times 10 \mathrm{~cm}$; closed arms: $50 \times 10 \times 40 \mathrm{~cm}$; elevation: $50 \mathrm{~cm}$ ) is a valid, reliable measure of anxiety, as well as the anxiolytic effects of drugs, including the BZs (Pellow et al, 1985; Rodgers and Dalvi, 1997). Before hippocampal slice preparation, rats were moved to a novel environment $30-60 \mathrm{~min}$ prior to placement in the plus-maze. All testing was carried out in a 144 sq. ft. room, illuminated with a single $40 \mathrm{~W}$, high-intensity bulb providing ambient light. Groups of FZP-withdrawn and control rats received no prior injection, vehicle or glutamate antagonist treatment as indicated in the text. All rats were naïve to the plus-maze and were tested only once between 0900 and $1100 \mathrm{~h}$. The maze was cleaned with $100 \%$ ethanol, then a damp cloth prior to placement of rats in the center of the maze facing an open arm. The number of arm entries and time spent in open- and closed arms were recorded for $5 \mathrm{~min}$ by an observer in the same room.

\section{Statistical Analysis}

Temporal analysis of whole-cell currents and plus-maze data from saccharin control and FZP-withdrawn rats were compared by MANOVA with post hoc analysis by the method of Scheffé $(p<0.05)$. Differences in peak mEPSC 
amplitude between neurons from control and FZP-withdrawn rats were also detected by shift of the relative cumulative frequency distribution of event amplitudes using the Kolmogorov-Smirnov test $(p<0.001)$. CA1 neuron spike discharge frequency was analyzed by repeated measures ANOVA with post hoc analysis of drug effect, by the method of Scheffé. Residual BZ effects on mIPSC properties were compared in neurons from control and FZP-treated rats by paired Student's $t$-test $(p<0.05)$. Whole-cell currents and plus-maze data from glutamate antagonist-injected control and FZP-withdrawn rats were compared by 2-factor ANOVA with post hoc analysis of drug effect by Student's $t$-test using Bonferroni's correction ( $p \leqslant 0.05 / k$, where $k=$ number of comparisons) to reduce Type I error (Cupples et al, 1984).

\section{Materials}

Tetrodotoxin (TTX) was purchased from Alamone Laboratories (Jerusalem, Israel). APV (DL-2-amino-5 phosphonovaleric acid), DNQX (6,7-dinitroquinoxaline-2,3-done), lidocaine $N$-ethyl bromide quaternary salt (QX-314), MK801, picrotoxin and FZP dihydrochloride were obtained from Research Biochemicals International division of Sigma-Aldrich Chemical Co. (St Louis, MO). Desalkyl-FZP and flumazenil were from Hoffman-LaRoche Inc. (Nutley, $\mathrm{NJ})$. The $\mathrm{GABA}_{\mathrm{B}}$ antagonist, CGP-35348, was a gift from Dr MF Pozza (CIBA-Geigy AG, Basel, Switzerland). GYKI-
52466, 4-AP and all other chemicals were obtained from Sigma-Aldrich.

\section{RESULTS}

\section{Temporal Regulation of Glutamate Receptor Function during FZP Withdrawal}

AMPAR mEPSCs and evoked NMDAR EPSCs were recorded in CA1 pyramidal neurons from 0-, 1-, 2-, and 4-day FZPwithdrawn rats (average FZP dose per each of eight groups: $130.6 \pm 3.1-134.8 \pm 1.9 \mathrm{mg} / \mathrm{kg} / \mathrm{day}, n=6-8$ rats per group).

AMPAR-mediated mEPSCS. Spontaneous inward mEPSCs were observed in neurons voltage-clamped at $-80 \mathrm{mV}$ (Figure 1a, b). Peak mEPSC amplitude in neurons from 1-day FZP-withdrawn rats was significantly increased (Figure 1a; Table 1), consistent with the rightward shift of the relative cumulative frequency distribution of mEPSC amplitudes (Figure 1c; Kolmogorov-Smirnov, K-S test, $p<0.001)$. Rats injected with saline $24 \mathrm{~h}$ prior to slice preparation, which were vehicle controls in the NMDAR antagonist studies (Figure $6 \mathrm{a}, \mathrm{b}$ ), were used for comparison of peak mEPSC amplitude between 2-day FZP-withdrawn and saccharin control rats. The increase in mEPSC amplitude (Figure 1b; Table 1) and rightward shift of the relative cumulative frequency distribution of mEPSC amplitudes (Figure 1d; K-S test, $p<0.001$ ) supported our

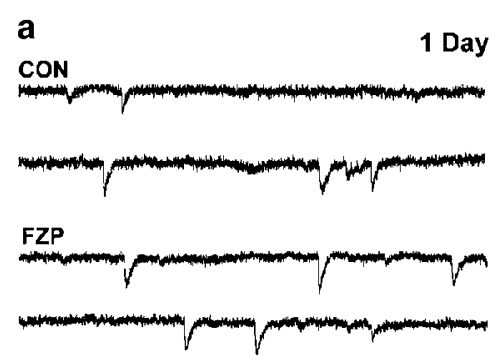

$\mathbf{C}$

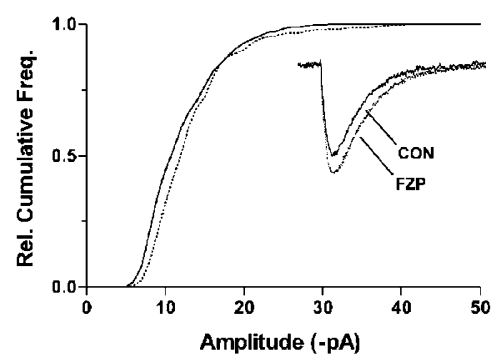

b

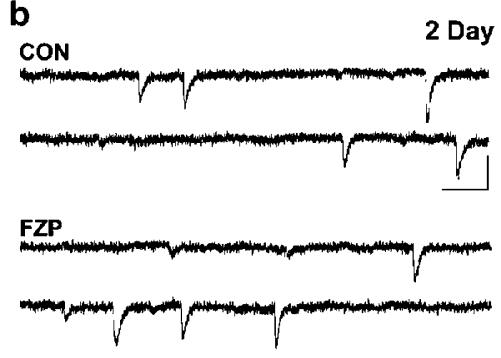

d

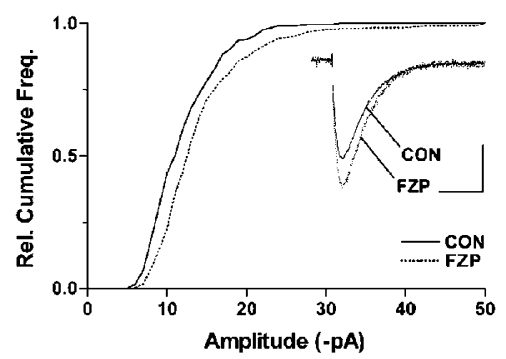

Figure I AMPAR-mediated mEPSCs in hippocampal CAI neurons during FZP withdrawal. (a, b) Representative traces of mEPSCs from individual CAI neurons from control (top) and FZP-withdrawn (bottom) rats recorded in the presence of I $\mu \mathrm{M}$ TTX, $50 \mu \mathrm{M}$ picrotoxin, $25 \mu \mathrm{M}$ CGP-35348 and I0 $\mu \mathrm{M}$ glycine. Neurons from I-day (a) or 2-day (b) FZP-withdrawn rats showed an increased mean mEPSC amplitude when compared to neurons from control rats. Scale: $15 \mathrm{pA} / 10 \mathrm{~ms}$. (c) Relative cumulative frequency distribution of mEPSC amplitudes in CAI neurons (CON, $n=10$ cells/six rats; FZP, $n=12$ cells/ seven rats) from saccharin vehicle or I-day FZP-withdrawn rats. The distribution of mEPSC amplitudes from FZP-withdrawn rats was significantly shifted to the right indicating an increase in the proportion of larger amplitude events (Kolmogorov-Smirnov test; $p<0.00$ I). (c) Inset: Representative average mEPSC from a control CAI neuron and a neuron from an FZP-withdrawn rat different from those shown in (a). On day I of withdrawal, there was an increase in average mEPSC amplitude in CAI neurons relative to control neurons. Scale: $5 \mathrm{pA} / \mathrm{IOms}$. (d) Relative cumulative frequency distribution of mEPSC amplitudes in CAI neurons (CON, $n=5$ cells/four rats; FZP, $n=7$ cells/six rats) from saccharin vehicle or 2-day FZP-withdrawn rats. The distribution of mEPSC amplitudes in CAI neurons from FZP-withdrawn rats was significantly shifted to the right indicating an increase in the proportion of larger amplitude events ( $\mathrm{K}-\mathrm{S}$ test; $p<0.00 \mathrm{I}$ ). (d) Inset: Representative average mEPSC from a control CAI neuron and a neuron from an FZP-withdrawn rat different from those shown in (b). On day 2 of withdrawal, there was an increase in average mEPSC amplitude in CAI pyramidal neurons relative to control neurons. Scale: $5 \mathrm{pA} / \mathrm{IO} \mathrm{ms}$. 
Table I mEPSC Properties in CAI Neurons During FZP Withdrawal

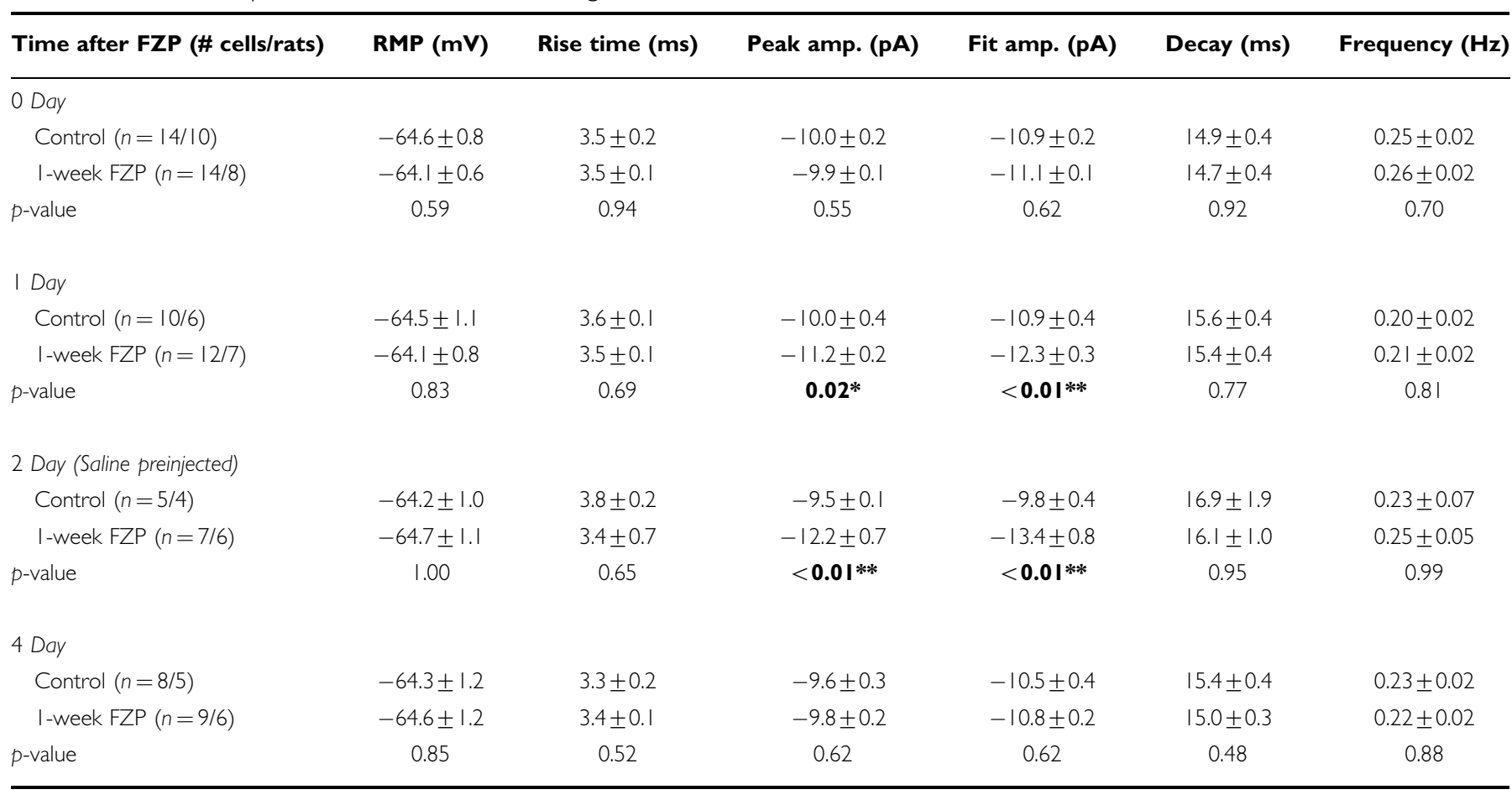

Values represent mean \pm SEM.

Significant difference $*(p \leqslant 0.05)$, *** $(p<0.01)$ between control and FZP-treated groups by ANOVA with post hoc comparisons by the method of Scheffé

previous finding of increased peak mEPSC amplitude in 2day FZP-withdrawn rats (Van Sickle and Tietz, 2002). No differences were observed in peak mEPSC amplitude in CA1 neurons between control and 0- or 4-day FZP-withdrawn rats (Table 1), and no differences were found in RMP, 10$90 \%$ rise time, decay constant $(\tau)$ or frequency of events between control and FZP-withdrawn rats at any time-point studied (Table 1). The temporal pattern of changes in peak AMPAR-mediated mEPSC amplitude in CA1 pyramidal neurons during FZP withdrawal is provided in Figure $3 \mathrm{a}$.

NMDAR-mediated eEPSCS. Inward NMDAR-mediated eEPSCs were evoked in slices from the same rats by halfmaximal stimulation of Schaffer collateral axons. Neurons were voltage-clamped at holding potentials from -80 to $+40 \mathrm{mV}$ to examine the current-voltage $(I-V)$ relationship of NMDA eEPSCs. The evoked NMDA currents in CA1 neurons from 0-, 1-, 2-, and 4-day FZP-withdrawn rats demonstrated the characteristic 'J-shape' of ligand-gated/ voltage-sensitive NMDARs. No differences in RMP between neurons from control and FZP-withdrawn rats were observed at any time-point studied. The $I-V$ curves generated in neurons from 0 - and 4-day withdrawn rats (data not shown) were equivalent to those determined in 1day rats (Figure $2 \mathrm{a}$ ). While it appears on inspection, that the $I-V$ curve generated in uninjected control rats 1 day after FZP withdrawal is different from that in saline-injected control rats 2 days after withdrawal, statistical analysis did not bear this out $(p>0.05)$. The evoked EPSC amplitude in CA1 neurons from saline-injected, 2-day FZP-withdrawn rats in comparison to their matched saline-injected control group was significantly reduced at holding potentials from -60 to $-20 \mathrm{mV}(p<0.05$; Figure $2 \mathrm{~b})$. Thus, the reduction in maximal NMDA-mediated currents in 2 day FZP-withdrawn rats is in agreement with our previous observation of reduced NMDAR function and NMDA efficacy in 2-day FZP-withdrawn rats without prior saline injection (Van Sickle et al, 2002). With respect to maximal current amplitude, there was a significant reduction at $V_{\mathrm{H}}=-20 \mathrm{mV}(\mathrm{CON}:-170.6 \pm 13.1 \mathrm{pA}$; FZP: $-98.6 \pm 7.8 \mathrm{pA}$, $p=0.008)$, but not $V_{\mathrm{H}}=+40 \mathrm{mV}(\mathrm{CON}:+162.8 \pm 16.5 \mathrm{pA}$; FZP: $121.2 \pm 6.6 \mathrm{pA}, p=0.65)$. There was no change in NMDAR eEPSC amplitude in CA1 neurons from 0 - (10 cells/ six rats), 1- (7 cells/five rats) or 4 - (7 cells/four rats) day FZP-withdrawn rats. The temporal pattern of changes in NMDAR function at the $-20 \mathrm{mV}$ holding potential in CA1 pyramidal neurons during FZP withdrawal is summarized in Figure $3 b$.

\section{Temporal Expression of Anxiety-Like Behavior during FZP Withdrawal}

Since glutamate receptors have been implicated in the development and expression of behaviors indicative of $\mathrm{BZ}$ withdrawal (Steppuhn and Turski, 1993), a behavioral correlate for the observed temporal pattern of the regulation of hippocampal AMPAR and NMDAR function was sought. The elevated plus-maze was used to assess temporal changes in anxiety-like behavior in rats during withdrawal from 1-week FZP treatment (average FZP dose per each of four groups: $130.5 \pm 2.8-133.7 \pm 4.1 \mathrm{mg} / \mathrm{kg} / \mathrm{day}, n=7-8$ rats/ group). 
a

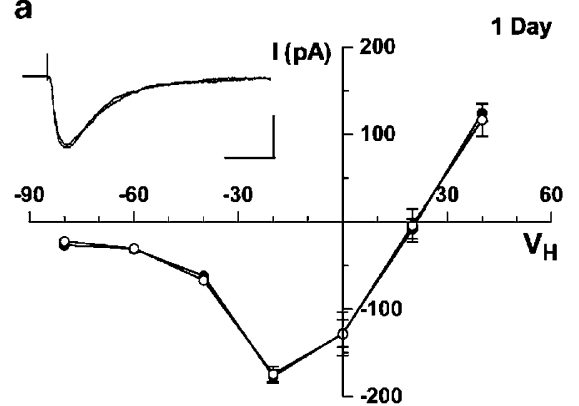

b

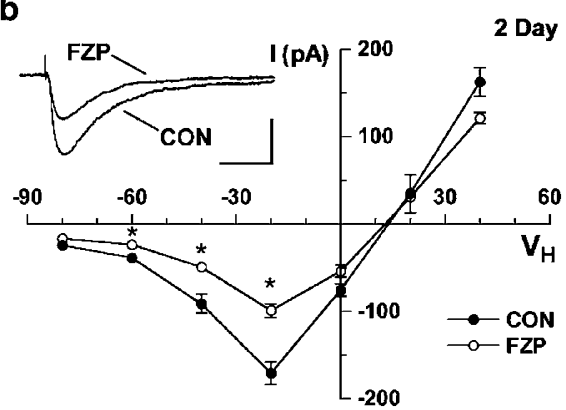

Figure 2 NMDAR EPSCs evoked by Schaffer collateral stimulation of CAI neurons in hippocampal slices during FZP withdrawal. Insets (a) and (b) Representative traces of evoked NMDAR EPSCs (eEPSCs) generated at $V_{H}=-20 \mathrm{mV}$ in individual CAI neurons from saccharin vehicle and FZP-withdrawn rats recorded in the presence of I mM MgCl $2,10 \mu \mathrm{M}$ DNQX, $50 \mu \mathrm{M}$ picrotoxin, $25 \mu \mathrm{M}$ CGP-35348 and I0 $\mu \mathrm{M}$ glycine. Scale: I00 pA/I00 ms. (a) and (b) Averaged current-voltage $(I-V)$ curves of peak eEPSC amplitude $\left(V_{H}=-80\right.$ to $+40 \mathrm{mV}$ ) generated in CAI neurons (control: closed circles; FZPwithdrawn: open circles). There was no change in the $I-V$ curve across all holding potentials evaluated in neurons from I-day FZP-withdrawn rats (CON, $n=7$ cells/six rats; FZP, $n=7$ cells/five rats). There was a significant decrease in NMDAR eEPSC amplitude at holding potentials from -60 to $-20 \mathrm{mV}$ in CAI neurons from 2-day FZP-withdrawn rats (CON, $n=7$ cells/five rats; FZP, $n=9$ cells/six rats). There were no significant differences in the average stimulus intensity $(0.3-0.4 \mathrm{~mA})$ required to elicit half-maximal eEPSCs between control and FZP-withdrawn rats. Data were analyzed by MANOVA with post hoc comparison of means by the method of Scheffé. Asterisks denote significant differences between control and FZP-withdrawn groups, $p \leqslant 0.05$.
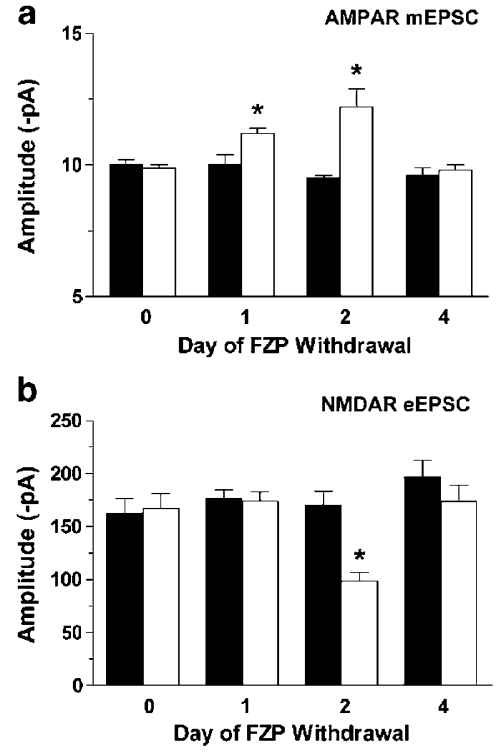

Figure 3 Temporal pattern of glutamate receptor-mediated current regulation in CAI pyramidal neurons during FZP withdrawal. (a) Average AMPAR mEPSC amplitude $\left(V_{H}=-80 \mathrm{mV}\right)$ in CAI neurons from control (black bars) or FZP-withdrawn rats (gray bars) euthanized at 0, I, 2, or 4 days of withdrawal from FZP. (b) Average NMDAR eEPSC amplitude $\left(V_{H}=-20 \mathrm{mV}\right)$ in CAI neurons from control or FZP-withdrawn rats euthanized at 0, I, 2, or 4 days of withdrawal from FZP. Numbers of cells and rats at each time-point and drug condition are reported in Table I and Figure 2. Data were analyzed by MANOVA with post hoc comparison of means by the method of Scheffé. Asterisks denote significant differences between control and FZP-withdrawn groups, $p \leqslant 0.05$.

A significant reduction in the percentage of open-arm entries (Figure 4a; CON: 40.8 $\pm 3.8 \%$, FZP: $27.8 \pm 3.9 \%$; $p<0.01$ ), as well as the percentage of open-arm time (Figure $4 \mathrm{~b}$; CON: $33.7 \pm 5.3 \%$, FZP: $10.5 \pm 2.6 \%$; $p<0.01$ ), was observed in 1-day FZP-withdrawn rats relative to saccharin control rats. No differences were found in the percentage of open-arm entries or open-arm time between control and 0-, 2-, or 4-day FZP-withdrawn rats. To demonstrate that increased anxiety in 1-day FZP-withdrawn
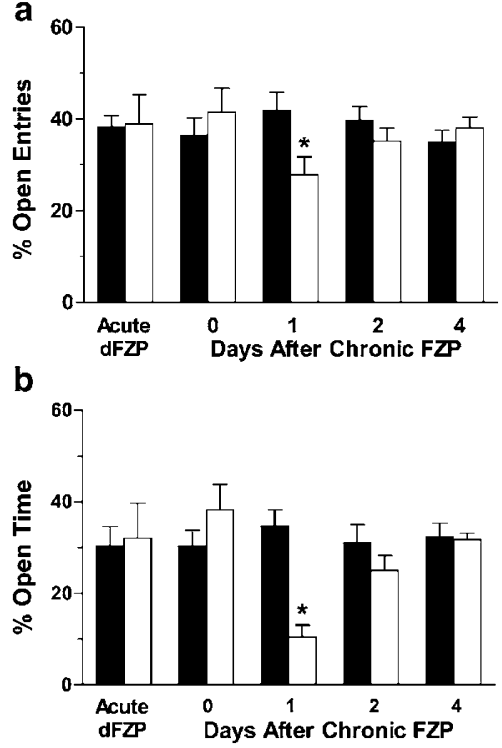

Figure 4 Temporal pattern of anxiety-like behavior measured in an elevated plus-maze during FZP withdrawal. Rats were tested I day after an acute gavage of desalkyl-FZP (CON: $n=7 ; d-F Z P, n=8)$ or at $0(C O N$ : $n=8$; FZP, $n=8)$, I (CON: $n=9 ;$ FZP, $n=8), 2(C O N: n=7 ; F Z P, n=8)$ or 4 (CON: $n=7$; FZP, $n=7$ ) days of withdrawal from FZP (CON: black bars; FZP gray bars). (a) Open-arm entries expressed as a percent of total entries. There was a significant reduction (33\%) in open-arm entries in Iday FZP-withdrawn rats relative to vehicle-treated control rats that was not evident after acute desalkyl-FZP treatment nor at 0 , 2, or 4 days of FZP withdrawal. (b) Open-arm time expressed as a percent of total time. Using this measure, only I-day FZP-withdrawn rats also demonstrated increased anxiety-like behavior, measured as a significant reduction (70\%) in the time spent on open arms. Data were analyzed by MANOVA with post hoc comparison of means by the method of Scheffé. Asterisks denote significant differences between control and FZP-withdrawn groups, $p \leqslant 0.05$.

rats was specific to withdrawal from chronic BZ exposure, rats were also tested in the elevated plus-maze 1 day after acute desalkyl-FZP $(2.5 \mathrm{mg} / \mathrm{kg})$ or control emulsion gavage. There was no difference in the percentage of open-arm entries or open-arm time between control emulsion and desalkyl-FZP-treated rats (Figure 4). Motor activity, 
measured by the number of closed-arm entries, was not different between control and acute desalkyl-FZP-treated or FZP-withdrawn rats at any time-point tested $(p=0.10$ $0.91)$.

\section{Effect of FZP Withdrawal on CA1 Neuron Excitability}

To determine whether enhanced AMPAR-mediated currents may contribute to CA1 neuron hyperexcitability and expression of withdrawal-anxiety in 1-day FZP-withdrawn rats, prior to downregulation of NMDAR-mediated currents, 4-AP-induced endogenous glutamate release was examined by its capacity to increase CA1 neuron spike discharges in hippocampal slices. CA1 neurons are not spontaneously active, and thus baseline spike discharges were infrequent during ACSF superfusion (Figure 5).

In the CA1 region of control slices, 4-AP increased spike discharges from $2-3$ per $5 \mathrm{~min}$ to $8-13$ per $5 \mathrm{~min}$ across the $40 \mathrm{~min}$ drug superfusion (Figure 5). While
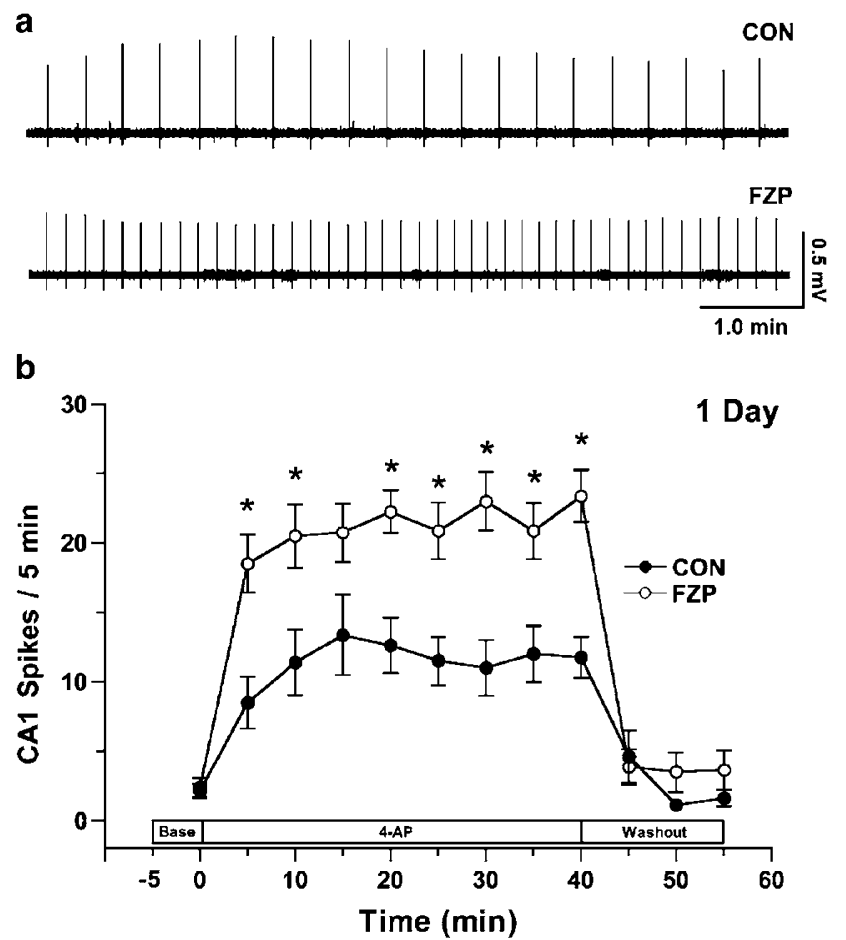

Figure 5 CAI neuron excitability during FZP withdrawal. Extracellular recordings of 4-aminopyridine (4-AP)-induced spike discharges were made in the CAI pyramidal cell layer of hippocampal slices from control and I-day FZP-withdrawn rats. A $5 \mathrm{~min}$ baseline recording during ACSF superfusion was followed by 40 min superfusion with $55 \mu$ M 4-AP. Spike discharges were recorded for an additional 15 min during drug washout with ACSF. The frequency of spike discharges was measured per 5 min epoch. (a) Representative traces of spike discharges in slices from control (top) and I-day FZP-withdrawn (bottom) rats taken during the first 5-10 min epoch of 4-AP superfusion. (b) CAI neuron hyperexcitability in I-day FZP-withdrawn rats. There was a significant increase in 4-APinduced spike discharges in slices from FZP-withdrawn rats in comparison to control rats suggesting hyperexcitability of the hippocampal CAI neuron population in I-day FZP-withdrawn rats. Data were analyzed by repeated measures ANOVA with post hoc analysis of drug effect by the method of Scheffé. Asterisks denote significant differences between control and FZP-withdrawn groups, $p \leqslant 0.05$. spontaneous CA1 neuron activity was similar in slices from control and 1-day FZP withdrawn rats, there was a significant two-fold (20-24 spikes) increase in frequency of 4-AP-induced spiking in slices from 1-day FZP-withdrawn rats beginning 5 min after start of 4-AP superfusion and persisting for the duration of drug superfusion (Figure 5b). Upon drug washout, the CA1 neuron population response returned to baseline in slices from both control and 1-day FZP-withdrawn groups.

\section{GABAR-Mediated Function during FZP Withdrawal}

We previously reported a reduction in GABAR mIPSC amplitude 2 days after FZP treatment (Zeng and Tietz, 1999). Since reduced GABAR-mediated inhibition could contribute to withdrawal-anxiety (Figure 4) and CA1 neuron hyperexcitability (Figure 5), it was necessary to determine if mIPSC amplitude was also reduced 1 day after FZP treatment. Given that the concentration of FZP metabolites in brain 1 day after the end of FZP treatment is $<10 \%$ of that immediately after the end of treatment $(0.57 \mu \mathrm{M}$, diazepam equivalents; Xie and Tietz, 1992), the concentration of residual drug in the hippocampus could be $\sim 6 \mathrm{nM}$, perhaps sufficient to potentiate GABAR-mediated inhibition. Therefore, the effect of the BZ antagonist, flumazenil $(1 \mu \mathrm{M})$ to modify mIPSCs was evaluated. Neither baseline mIPSC amplitude (CON: $-23.9 \pm 2.1 \mathrm{pA}, n=4$ cells/four rats; FZP: $-20.4 \pm 2.6 \mathrm{pA}, n=5$ cells/four rats) nor decay (CON: $25.1 \pm 0.4 \mathrm{~ms}$; FZP: $25.6 \pm 1.0 \mathrm{~ms}$ ) was modified by flumazenil superfusion. There was no decrease in mIPSC amplitude or change in event decay or frequency after acute BZ treatment with desalky-FZP or 1 day after FZP treatment (Table 2).

\section{MK-801 Reverses Downregulation of NMDAR Function during FZP Withdrawal}

Given that the disappearance of BZ-induced anxiety between 1 and 2 days of FZP withdrawal (Figure 4) was concurrent with decreased NMDAR function in CA1 pyramidal neurons (Figure 2), we hypothesized that downregulation of NMDAR function in CA1 neurons may have prevented AMPAR-mediated expression of withdrawalanxiety. Using a strategy similar to that used to reverse GABAergic BZ tolerance mechanisms (Tietz et al, 1999), we predicted that antagonism of NMDAR activation earlier during FZP withdrawal may prevent subsequent downregulation of NMDAR function in CA1 neurons and alter expression of $\mathrm{BZ}$ withdrawal-anxiety. To evaluate this hypothesis, control and 1-day FZP-withdrawn rats were systemically injected with saline or MK-801 $(0.25 \mathrm{mg} / \mathrm{kg}$, i.p.) then tested 1 day later in the elevated plus-maze prior to slice preparation of these 2-day withdrawn rats for electrophysiological studies.

In studies of evoked NMDA EPSCs in CA1 pyramidal neurons, no differences were detected in RMP between control and FZP-withdrawn rats that received vehicle or MK-801 treatment (CON/VEH: $-66.0 \pm 1.1 \mathrm{mV}, n=6$ cells/ four rats; FZP/VEH: $-64.8 \pm 0.8 \mathrm{mV}, n=6$ cells/three rats; CON/MK-801: $-66.1 \pm 0.9 \mathrm{mV}, n=7$ cells/six rats; FZP/MK801: $-65.9 \pm 0.4 \mathrm{mV}, n=7$ cells/five rats). As illustrated in Figures $2 \mathrm{~b}$ and $6 \mathrm{a}, \mathrm{b}$, vehicle injection of saccharin control 
Table 2 mIPSC Properties in CAI Neurons in FZP-Treated Rats

\begin{tabular}{|c|c|c|c|c|c|c|}
\hline BZ treatment (\# cells/rats) & RMP (mV) & Rise time (ms) & Peak amp. (pA) & Fit amp. (pA) & Decay (ms) & Frequency $(\mathrm{Hz})$ \\
\hline \multicolumn{7}{|l|}{ Acute } \\
\hline Control $(n=6 / 3)$ & $-61.0 \pm 2.5$ & $1.20 \pm 0.11$ & $-25.5 \pm 3.3$ & $-24.4 \pm 3.1$ & $32.1 \pm 3.0$ & $0.63 \pm 0.14$ \\
\hline Desalkyl-FZP $(n=6 / 4)$ & $-64.3 \pm 2.0$ & $1.09 \pm 0.07$ & $-29.1 \pm 4.3$ & $-28.1 \pm 4.2$ & $28.2 \pm 2.1$ & $0.64 \pm 0.17$ \\
\hline$p$-value & 0.32 & 0.42 & 0.52 & 0.49 & 0.31 & 0.97 \\
\hline Control $(n=14 / 6)$ & $-63.1 \pm 0.9$ & $1.03 \pm 0.04$ & $-24.9 \pm 2.2$ & $-23.6 \pm 2.1$ & $25.1 \pm 0.4$ & $0.75 \pm 0.09$ \\
\hline I-week FZP $(n=\mid 4 / 8)$ & $-64.1 \pm 0.9$ & $1.00 \pm 0.02$ & $-24.6 \pm 1.4$ & $-23.4 \pm 1.3$ & $25.6 \pm 1.0$ & $0.68 \pm 0.07$ \\
\hline$p$-value & 0.49 & 0.43 & 0.91 & 0.94 & 0.76 & 0.54 \\
\hline
\end{tabular}

Values represent mean \pm SEM.

a

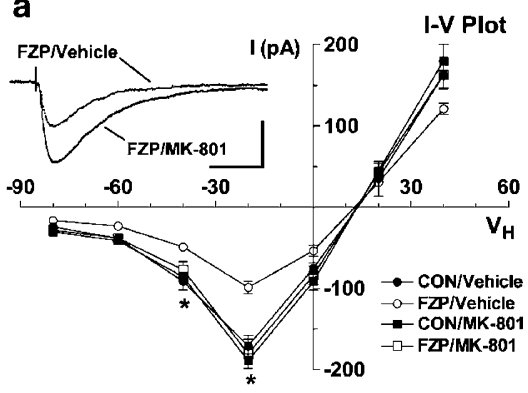

C

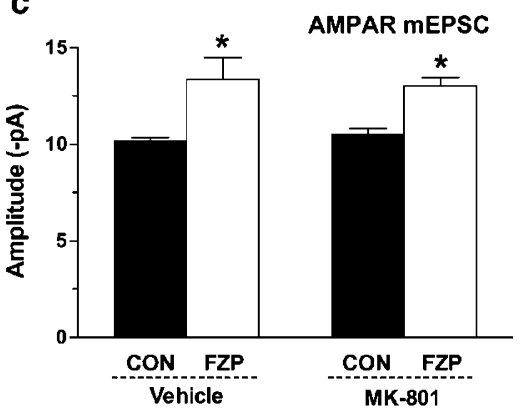

b

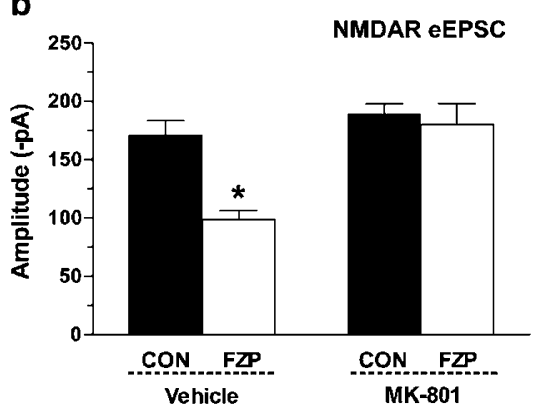

d

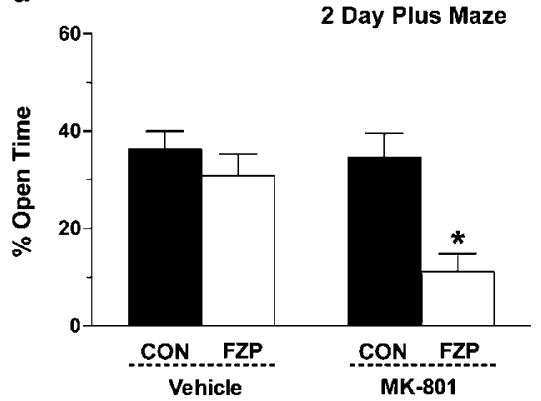

Figure 6 Effect of systemic MK-80I injection on excitatory currents in CAI neurons and anxiety-like behavior during FZP withdrawal. A single injection of the noncompetitive NMDAR antagonist, MK-80 I $(0.25 \mathrm{mg} / \mathrm{kg}$, i.p.) or saline (I ml $/ \mathrm{kg}$, i.p.) vehicle was given to rats on day I of withdrawal from FZP treatment. Rats were tested I day later in the elevated plus-maze, followed by hippocampal slice preparation for electrophysiological recording. (a) Averaged current-voltage $(I-V)$ curves of peak NMDAR eEPSC amplitude $\left(V_{H}=-80\right.$ to $\left.+40 \mathrm{mV}\right)$ generated in CAI neurons from 2-day FZP-withdrawn rats. As shown in Figure 2, NMDAR eEPSC amplitude was significantly reduced at holding potentials from -60 to $-20 \mathrm{mV}$ in neurons from vehicle-injected FZPwithdrawn rats (open circles, $n=6$ cells/three rats) in comparison to neurons from vehicle-injected control rats (closed circles, $n=6$ cells/four rats). MK-80 I reversed the reduced NMDAR eEPSC amplitude in neurons from FZP-withdrawn rats (open squares, 7 cells $/ n=5$ rats), yet had no effect on neurons from control rats (closed squares, 7 cells $/ n=6$ rats). (b) Average NMDAR eEPSC amplitude $\left(V_{H}=-20 \mathrm{mV}\right)$ in CAI neurons from vehicle or MK-80 I-injected control (black bars) or 2-day FZP-withdrawn (gray bars) rats. (c) Average AMPAR mEPSC amplitude $\left(V_{H}=-80 \mathrm{mV}\right)$ in CAI neurons from control (black bars) or 2-day FZP-withdrawn rats (gray bars). Neither vehicle nor MK-80I injection had an effect on upregulation of AMPAR mEPSC amplitude. (d) Openarm time on an elevated plus-maze, expressed as a percent of total time, following vehicle or MK-80I injection. Control (black bars) and 2-day FZPwithdrawn rats (gray bars) injected with vehicle showed no evidence of anxiety-like behavior. MK-80I injection resulted in the appearance of anxiety, measured as a significant reduction $(-68 \% ; p<0.0 \mathrm{I})$ in the percentage of open arm time, in 2-day FZP-withdrawn rats. Asterisks denote significant differences between control and FZP-withdrawn groups by two-factor ANOVA with post hoc analysis of drug effect in antagonist-treated groups by Student's $t$-test using Bonferroni's correction ( $p<0.05 / k$, where $k=$ number of comparisons).

and 1-day FZP-withdrawn rats did not modify downregulation of NMDAR function in CA1 neurons. MK-801 injection (Figure 6a, b) also did not modify NMDA EPSC amplitude in control neurons. However, in neurons from 2-day FZP-withdrawn rats injected with MK-801 the pre- ceding day, evoked NMDA EPSC amplitudes were returned to control levels at all holding potentials $\left(V_{\mathrm{H}}=-60\right.$ to $-20 \mathrm{mV})$ and were significantly different $(p<0.01)$ from those in 2-day FZP-withdrawn rats receiving saline injection. 
In studies of AMPAR mEPSCs in CA1 neurons from the same rats, there was no difference in RMP (Table 1; CON/ MK-801: $-64.2 \pm 1.2 \mathrm{mV}, n=11$ cells/nine rats; FZP/MK801: $-64.0 \pm 1.3 \mathrm{mV}, n=9$ cells/eight rats), $10-90 \%$ rise time, decay or frequency of events between control and 2day FZP-withdrawn rats that received vehicle or MK-801 injection. However, there was a significant main effect of FZP treatment on peak mEPSC amplitude $\left(\mathrm{F}_{1,28}=28.8\right.$, $p<0.001)$. Average AMPAR mEPSC amplitude in CA1 neurons from FZP-withdrawn rats remained increased after MK-801 (CON/MK-801: $-9.6 \pm 0.3$ pA, FZP/MK-801: $-11.8 \pm 0.4 \mathrm{pA} ; p<0.01$ ), or vehicle injection (Table 1; Figure 6c).

\section{MK-801 'Unmasks' Anxiety-Like Behavior}

The effect of NMDAR antagonism on BZ withdrawalanxiety in the elevated plus-maze was evaluated in the same 2-day FZP-withdrawn rats. There was a significant interaction between FZP and MK-801 treatments with respect to the percentage of open-arm entries $\left(\mathrm{F}_{1,28}=6.45, p<0.02\right)$ and open-arm time $\left(\mathrm{F}_{1,28}=7.66, p<0.01\right)$. In control $(n=7)$ and 2-day FZP-withdrawn rats (average FZP dose: $134.9 \pm 2.4 \mathrm{mg} / \mathrm{kg} /$ day; $n=7$ ), vehicle injection had no effect on the percentage of open-arm entries or open-arm time, similar to 2-day FZP-withdrawn rats that did not receive injections prior to testing (Figure 4). However, in 2-day FZP-withdrawn rats (average FZP dose: $137.8 \pm 3.6 \mathrm{mg} / \mathrm{kg} /$ day; $n=8$ ) injected with MK-801 on day 1 of withdrawal, there was a reduction in both the percentage of openarm entries (CON/MK-801: 39.6 $2.7 \%$, FZP/MK-801: $16.6 \pm 4.3 \%$ ) and open-arm time (Figure $6 \mathrm{~d}$; CON/MK-801: $34.6 \pm 4.9 \%, \mathrm{FZP} / \mathrm{MK}-801: 11.2 \pm 3.7 \%)$ on day 2 relative to controls $(n=7)$. This was similar to 1 -day FZP-withdrawn rats that demonstrated increased anxiety-like behavior (Figure 4). The number of closed-arm entries was not different between saline- or MK-801-injected control and 2-day FZP-withdrawn rats.
GYKI-52466 Reverses Upregulation of AMPAR Function and Prevents Anxiety-Like Behavior during FZP Withdrawal

Since anxiety in 1-day FZP-withdrawn rats corresponded with increased AMPAR-mediated function in CA1 pyramidal neurons, we hypothesized that antagonism of AMPAR activation at the onset of FZP withdrawal may prevent upregulation of AMPAR function in CA1 neurons and alter expression of $\mathrm{BZ}$ withdrawal-anxiety. To evaluate this hypothesis, control and FZP-withdrawn rats were injected with $1 \%$ TWEEN-20 vehicle or GYKI-52466 $(0.5 \mathrm{mg} / \mathrm{kg})$ immediately following removal of FZP from the drinking water. FZP-withdrawn rats were then tested 1 day later in the elevated plus-maze prior to hippocampal slice preparation for studies of AMPAR function.

In studies of AMPAR mEPSCs in CA1 neurons, there was no difference in resting membrane potential (CON/VEH: $-60.3 \pm 1.0 \mathrm{mV}, n=9$ cells/eight rats; FZP/VEH: $-60.1 \pm$ $1.2 \mathrm{mV}, n=8$ cells/six rats; CON/GYKI: $-58.6 \pm 1.2 \mathrm{mV}$, $n=9$ cells/seven rats; FZP/GYKI: $-58.0 \pm 0.9 \mathrm{mV}, n=8$ cells/five rats), $10-90 \%$ rise time, decay or frequency of AMPAR-mediated events between control and 1-day FZPwithdrawn rats that received vehicle or GYKI-52466 injection the previous day. However, there was a significant interaction between FZP and GYKI-52466 treatments with respect to mEPSC amplitude $\left(\mathrm{F}_{1,33}=6.73, p=0.014\right)$. Similar to other groups of 1-day FZP withdrawn rats (Figure 1, Table 1), AMPAR mEPSC amplitude in CA1 neurons was upregulated in comparison to controls and unmodified by vehicle injection (Figure 7a; CON/VEH: $-8.7 \pm 0.5 \mathrm{pA}, \mathrm{FZP} / \mathrm{VEH}:-11.3 \pm 0.4 \mathrm{pA})$. GYKI-52466 injection (Figure $7 \mathrm{a}$ ) at the end of the drug treatment period had no effect on AMPAR mEPSC amplitude in control neurons; however, average AMPAR mEPSC amplitude returned to control levels in neurons from 1-day FZPwithdrawn rats (CON/GYKI: $-9.5 \pm 0.8 \mathrm{pA}$; FZP/GYKI: $-9.0 \pm 0.6 \mathrm{pA})$.
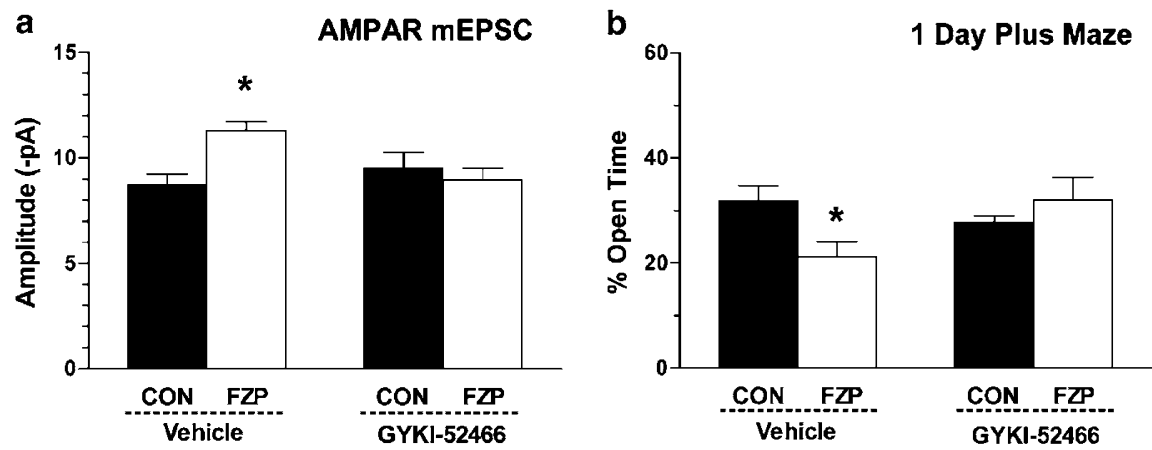

Figure 7 Effect of systemic GYKI-52466 injection on AMPAR-mediated currents in CAI neurons and anxiety-like behavior during FZP withdrawal. A single injection of the noncompetitive AMPAR antagonist, GYKI-52466 (0.5 mg/kg, i.p.) or $1 \%$ TWEEN-20 (0.5 ml $/ \mathrm{kg}$, i.p.) vehicle was given to rats immediately after removal of FZP from the drinking water. Rats were tested I day later in the elevated plus-maze, followed by hippocampal slice preparation for electrophysiological recording. (a) Average AMPAR mEPSC amplitude $\left(V_{H}=-80 \mathrm{mV}\right.$ ) in CAI neurons from control (black bars) or I-day FZPwithdrawn rats (gray bars). Vehicle injection had no effect on upregulation of AMPAR mEPSC amplitude in CAI neurons from I-day FZP-withdrawn rats relative to saccharin-treated control rats. Prior GYKI-52466 injection blocked upregulation of AMPAR mEPSC amplitude in CAI neurons from I-day FZPwithdrawn rats without effect on saccharin-treated control rats. (b) Open-arm time on an elevated plus-maze, expressed as a percent of total time, following vehicle or GYKI-52466 injection. Anxiety-like behavior, measured as a significant reduction $(-33 \%, p<0.02)$ in the percentage of open-arm time, was observed in I-day FZP-withdrawn, but not saccharin-treated control, rats after vehicle injection. Prior GYKI-52466 injection blocked the expression of anxiety-like behavior in I-day FZP-withdrawn rats. Data were analyzed by two-factor ANOVA with post hoc analysis of drug effect in antagonist-treated groups by Student's $t$-test using Bonferroni's correction ( $p<0.05 / k$, where $k=$ number of comparisons). 
The effect of AMPAR antagonism on BZ withdrawalanxiety was also evaluated in the elevated plus-maze in the same 1-day FZP-withdrawn rats. There was no main effect or interaction effect of GYKI-52466 treatment on control or 1-day FZP-withdrawn rats with respect to the number of closed-arm entries. However, there was a significant interaction $\left(\mathrm{F}_{1,28}=6.45, p=0.01\right)$ with respect to the percentage of open-arm time. In 1-day FZP-withdrawn rats (average FZP dose: $134.0 \pm 3.1 \mathrm{mg} / \mathrm{kg} / \mathrm{day} ; n=11$ ) injected with vehicle, there was a significant reduction in the percentage of open-arm time (Figure 7b; CON/VEH: $31.9 \pm 2.9 \%$, FZP/VEH: $21.3 \pm 2.8 \%$ ) relative to controls $(n=11)$, similar to 1-day FZP-withdrawn rats that did not receive antagonist injection (Figure 4). GYKI-52466 injection completely prevented reduction in the percentage of open-arm time $(32.1 \pm 4.3 \% ; n=10)$ and expression of anxiety-like behavior (Figure $7 \mathrm{~b}$ ) in 1-day FZP-withdrawn rats (average FZP dose: $134.9 \pm 2.7 \mathrm{mg} / \mathrm{kg} /$ day; $n=10$ ).

\section{DISCUSSION}

The present study reports several novel findings that suggest transient plasticity of hippocampal CA1 neuron AMPAR- and NMDAR-mediated excitation may contribute to a neurophysiological mechanism for expression of $\mathrm{BZ}$ withdrawal-anxiety after 1-week FZP treatment. Anxietylike behavior corresponded with enhanced AMPARmediated currents and hyperexcitability in CA1 neurons in 1-day FZP-withdrawn rats but was not observed in 2-day FZP-withdrawn rats, concurrent with downregulation of NMDAR-mediated currents, and despite persistently increased AMPAR-mediated currents. Antagonism of NMDAR activation on day 1 of withdrawal prevented reduced NMDAR-mediated currents in CA1 neurons from 2-day FZP-withdrawn rats and permitted the expression of withdrawal-anxiety. Antagonism of AMPAR activation immediately after cessation of FZP treatment prevented both increased AMPAR-mediated currents in CA1 neurons and expression of withdrawal-anxiety in 1-day FZP-withdrawn rats. The temporal pattern of glutamate receptormediated excitation during $\mathrm{BZ}$ withdrawal suggests that altered hippocampal CA1 neuron excitatory receptor function and excitability, as part of a more extensive 'anxiety-circuit', may contribute to expression of BZ withdrawal-anxiety, even following relatively short periods of $\mathrm{BZ}$ use.

The specific neural mechanisms underlying BZ withdrawal behavior are presently not well defined, but our findings suggest a temporal link between localized upregulation of CA1 neuron AMPARs (Van Sickle and Tietz, 2002), increases in AMPAR mEPSC amplitude (Figures 1, 3, 6 and 7), CA1 neuron hyperexcitability (Figure 5) and concomitant appearance of anxiety-like behavior in vivo (Figures 4, 6 and 7). Changes in AMPAR function were not present immediately at the end of FZP treatment (Figure 3; Table 1) suggesting that transient plasticity of AMPARs begins during the first $24 \mathrm{~h}$ of FZP withdrawal concurrent with the rapid elimination of FZP and its metabolites in the rat hippocampus during this time period (Lau et al, 1987; Xie and Tietz, 1992). Similarly, following chronic ethanol administration, fast AMPA/kainate receptor-mediated CA1 neuron synaptic potentials progressively increase from 2 to $6 \mathrm{~h}$ after cessation of ethanol consumption (Molleman and Little, 1995). In the present study, AMPAR changes preceded NMDAR changes (Figure 3), a temporal pattern, which parallels that observed following chronic diazepam (Steppuhn and Turski, 1993). Systemic GYKI-52466 prevented both increased AMPAR-mediated excitation in CA1 neurons and withdrawal-anxiety when injected at the onset of FZP withdrawal (Figure 7a and b), while MK-801 blocked downregulation of NMDAR-mediated currents in 2-day FZP-withdrawn rats. Normalization of NMDAR function in the latter group of rats facilitated expression of anxiety-like behavior. Together, these studies support a neural mechanism by which the imbalance in excitatory neurotransmission during $\mathrm{BZ}$ withdrawal is initially AMPAR-dependent and leads to recruitment of NMDAR-mediated neural circuits involved in expression of BZ withdrawal behaviors (Allison and Pratt, 2003). Physiologic downregulation of NMDAR-mediated currents and decreased efficacy of NMDA in isolated CA1 neurons (Van Sickle et al, 2002) between days 1 and 2 of FZP-withdrawal may represent a homeostatic mechanism that mitigates expression of withdrawal-anxiety. It will be of significant interest to determine the effect of early GYKI-52466 administration on NMDARmediated function in 2-day FZP-withdrawn rats, as lack of downregulation would provide further support that increased AMPAR activation is important in homeostatic regulation of NMDAR function in CA1 neurons.

Anxiety-like behavior during BZ withdrawal may involve a targeted upregulation of hippocampal AMPARs as suggested by increased AMPAR GluR1 subunits (Izzo et al, 2001) and AMPAR binding (Allison et al, 1999; Van Sickle and Tietz, 2002) in CA1 neurons, but not other hippocampal cell groups (Van Sickle and Tietz, 2002). Activity-dependent recruitment of AMPARs is well described (Liao et al, 2001; O'Brien et al, 1998; Turrigiano, 2000) and is a final common pathway mediating activity-dependent changes in synaptic efficacy at CA1 excitatory synapses both in vivo and in vitro (Baudry and Lynch, 2001; Liao et al, 1995; Lledo et al, 1998; Nayak et al, 1998; Zamanillo et al, 1999). Activitydependent changes in synaptic function are primarily the consequence of intracellular $\mathrm{Ca}^{2+}$-dependent biochemical cascades and involve changes in synaptic AMPAR number and/or function (Hayashi et al, 2000; Song and Huganir, 2002). A GABAR-mediated depolarizing potential, which is present in 2-day FZP-withdrawn CA1 neurons (Zeng et al, 1995), has been shown to activate NMDARs (Staley et al, 1995) and may contribute to increased postsynaptic $\mathrm{Ca}^{2+}$. mediated signal transduction. Thus, in the context of $\mathrm{BZ}$ withdrawal, the initial trigger for AMPAR upregulation, though as yet unidentified, may also involve $\mathrm{Ca}^{2+}$-mediated mechanisms similar to that which occur during other forms of activity-dependent neuronal plasticity (Nestler, 2001b).

If the neural circuits underlying withdrawal anxiety can be influenced by enhanced CA1 neuron AMPAR function, hippocampal slices from 1-day FZP withdrawn rats should demonstrate hyperexcitability. Therefore, the ability of 4-AP to induce CA1 neuron population discharges was also examined in vitro. The stimulatory action of $4-\mathrm{AP}$, a $\mathrm{K}+$ channel antagonist, is largely due to its effect on glutamatergic synaptic transmission, facilitating endogenous glutamate release, though it also enhances presynaptic 
GABA release (Salazar et al, 2003). Given that measures of presynaptic activity such as mIPSC and mEPSC frequency (Tables 1 and 2) are unaltered in FZP-withdrawn rats and since AMPAR (and GABAR) regulation is specific to CA1, and not CA3 or DG neurons (Chen et al, 1999, 2000; Poisbeau et al, 1999; Van Sickle and Tietz, 2002), the observed increase in CA1 neuron excitability in FZPwithdrawn rats can be attributed to postsynaptic mechanisms. Thus, the two-fold increase in spike discharge frequency in slices from 1-day FZP withdrawn rats most likely results from glutamate activation of upregulated AMPARs in CA1 neurons.

The ability of glutamate antagonist pretreatments to affect the regulation of hippocampal excitatory currents and expression of withdrawal-anxiety suggests that the hippocampus may have a prominent functional role within the neural circuits mediating BZ withdrawal-anxiety. However, since systemic antagonists can also inhibit glutamate receptors in other brain structures, modulation of other components of the neural circuits mediating anxiety-like behavior cannot be discounted. The effects of AMPAR antagonists to modify anxiety states are equivocal (KarczKubicha and Liljequist, 1995; Tarnawa and Vize, 1998). In preliminary studies, GYKI-52466 $(5.0 \mathrm{mg} / \mathrm{kg})$ was modestly anxiogenic, however, a lower dose of GYKI-52466 (0.5 mg/ $\mathrm{kg}$ ) had no significant effect on open-arm time in control rats (Figure $7 \mathrm{~b}$ ). Furthermore, the lack of effect on closedarm entries is consistent with a lack of effect on locomotor activity (Hauber and Andersen, 1993) and its short half-life in rodents (de Sarro et al, 1995). While MK-801 exhibits anxiolytic actions when administered acutely, these effects are short-lived ( $\leqslant 14 \mathrm{~h}$ for $0.4 \mathrm{mg} / \mathrm{kg}$, i.p.; Xie et al, 1995), and no differences in plus-maze behavior were evident between MK-801- and saline-injected control rats (Figure 6d). Thus, the temporal pattern of glutamate receptor function, CA1 neuron hyperexcitability and expression of withdrawal-anxiety, together with regulation by selective glutamate receptor antagonists, strongly implicates altered hippocampal glutamate receptor function in the behavioral manifestations of BZ withdrawal.

Chronic BZ receptor activation modifies the GABAergic system in brain regions with key roles in modulating anxiety states: frontal cortex, hippocampus, and amygdala (Chen et al, 1999; Millan, 2003; Tietz et al, 1986; Zeng and Tietz, 1999), and BZ withdrawal may provide the necessary stimulus for local homeostatic regulation of excitationinhibition in these brain areas. The septo-hippocampal system, for example, is a primary neural substrate of anxiety in that all clinically effective anxiolytics, including BZs, have the capacity to raise the septal stimulus intensity needed to drive hippocampal theta activity (McNaughton and Gray, 2000). The hippocampus contributes substantial excitatory input to the septal nucleus (Amaral and Witter, 1995), and pharmacologic antagonism of septal AMPARs results in decreased anxiety (Menard and Treit, 2000). Furthermore, direct hippocampal injection of the $\mathrm{BZ}$ midazolam produces anxiolytic actions in the elevated plus-maze, which are blocked by intraseptal injection of glutamate (Menard and Treit, 2001). Since hippocampal glutamatergic afferents to septal nucleus can regulate expression of anxiety in the elevated plus-maze (Menard and Treit, 2001), hippocampal hyperexcitability, as observed in the present study
(Figure 5), may provide a neurophysiological mechanism for expression of anxiety after drug withdrawal (Figure 4). Indeed, spectral analysis of hippocampal electrical activity during withdrawal from 1-week FZP reveals increased power of a $7 \mathrm{~Hz}$ (theta) peak (Poisbeau et al, 1997). Future study using direct injection of glutamate antagonists into hippocampus, amygdala, and septal nucleus during FZP withdrawal may help to clarify the specific role of hippocampal glutamate receptors in expression of FZP withdrawal-anxiety.

Nonetheless, the differential regulation of GABAergic function and GABAR subunits has also been suggested to contribute to hyperexcitability and withdrawal-anxiety following allosteric activation of GABARs. Increases in $\alpha 4$ subunit protein were implicated in withdrawal from ethanol (Matthews et al, 1998; Sanna et al, 2003) and BZs (Follesa et al, 2001), while neurosteroid treatment was associated with withdrawal-anxiety, upregulation of GABAR $\alpha 4$ subunits and a reduction in mIPSC decay (Smith, 2002). Although $\alpha 4$ subunit protein was upregulated immediately after 1-week FZP treatment (Chen et al, 2000), mIPSC decay was unaltered on days 1 and 2 of withdrawal (Table 2; Zeng and Tietz, 1999). The lack of change in mIPSC amplitude or decay when withdrawal-anxiety is present weakens support for GABAR-mediated mechanisms in the expression of BZ withdrawal-anxiety and suggests a more prominent role for glutamatergic-mediated mechanisms. Interestingly, $\alpha 2$-containing GABARs, important for BZ anxiolytic actions (Mohler et al, 2002), are localized to the soma and proximal dendrites of CA1 neurons (Nusser et al, 1996), where AMPAR-antagonist binding is increased during FZP withdrawal (Van Sickle and Tietz, 2002). It will be of significant interest to determine whether dysfunction of these functionally segregated, GABAR-containing synapses interacts with local glutamatergic synapses contributing to a neural circuit involved in BZ withdrawal-anxiety.

In summary, the present study provides evidence that AMPAR facilitation of NMDAR-mediated hippocampal pathways contributes to expression of anxiety-like behavior during withdrawal from prolonged BZ exposure. While tolerance to $\mathrm{BZ}$ actions may primarily involve changes at GABARs, BZ withdrawal-anxiety appears to involve alterations in hippocampal glutamate receptor-mediated excitation and excitability within the neural circuits mediating expression of anxiety-like behaviors. Given that many drugs of abuse induce similar manifestations of drug withdrawal (Nestler, 2002), localized plasticity of hippocampal CA1 neuron glutamate receptors may constitute a common neurophysiological mechanism for the expression of withdrawal-anxiety and contribute to drug dependence.

\section{ACKNOWLEDGEMENTS}

We thank Scott Lilly, Eugene Orlowski, William Ferencak III, Weixiang Ma and Frank Vandy for technical assistance. These studies were supported by National Institutes of Drug Abuse Grants F30-DA06041 (BJV) and R01-DA04075 (EIT). Portions of this work have appeared in abstract form: Van Sickle et al, Soc Neurosci Abstr 39.1, 2002. Tietz, EI, Abstract, GABA Aeceptors in Cellular and Network Excitability, 12th Neuropharmacology Conference, Orlando, USA; Elsevier Science: 24, 2002. 


\section{REFERENCES}

Allison C, Dunworth SJ, Stephens DN, Pratt JA (1999). Involvement of AMPA-receptors in benzodiazepine withdrawal and sensitization processes. Behav Pharmacol 10: S2.

Allison C, Pratt JA (2003). Neuroadaptive processes in GABAergic and glutamatergic systems in benzodiazepine dependence. Pharmacol Ther 98: 171-195.

Amaral DG, Witter MP (1995). Hippocampal Formation. In: Paxinos G (ed). The Rat Nervous System. Academic Press: New York. pp 443-463.

Andrews N, File SE, Fernandes C, Gonzalez LE, Barnes NM (1997). Evidence that the median raphé nucleus-dorsal hippocampal pathway mediates diazepam withdrawal-induced anxiety. Psychopharmacology (Berl) 130: 228-234.

Baudry M, Lynch G (2001). Remembrance of arguments past: how well is the glutamate receptor hypothesis of LTP holding up after 20 years? Neurobiol Learn Mem 76: 284-297.

Berke JD, Hyman SE (2000). Addiction, dopamine, and the molecular mechanisms of memory. Neuron 25: 515-532.

Carlezon WAJ, Nestler EJ (2002). Elevated levels of GluR1 in the midbrain: a trigger for sensitization to drugs of abuse? Trends Neurosci 25: 610-615.

Chen S, Huang X, Zeng XJ, Sieghart W, Tietz EI (1999). Benzodiazepine-mediated regulation of $\alpha 1, \alpha 2, \beta 1-3$ and $\gamma 2$ $\mathrm{GABA}_{\mathrm{A}}$ receptor subunit proteins in the rat brain hippocampus and cortex. Neuroscience 93: 33-44.

Chen S, Sieghart W, Fritschy J-M, Tietz EI (2000). Differential temporal regulation of rat hippocampal $\mathrm{GABA}_{\mathrm{A}}$ receptor (GABAR) subunits $(\alpha 1, \alpha 2, \alpha 3, \alpha 4, \alpha 5, \beta 1, \beta 2, \beta 3 \& \gamma 2)$ after discontinuation of chronic flurazepam treatment. Soc Neurosci Abstr 26: 632.

Cupples LA, Heeren T, Schatzkin A, Colton T (1984). Multiple testing of hypotheses in comparing two groups. Ann Intern Med 100: $122-129$.

de Sarro G, Chimirri A, de Sarro A, Gitto R, Grasso S, Giusti P et al (1995). GYKI 52466 and related 2,3-benzodiazepines as anticonvulsant agents in DBA/2 mice. Eur J Pharmacol 294: 411-422.

File SE, Fernandes C (1994). Dizocilpine prevents the development of tolerance to the sedative effects of diazepam in rats. Pharmacol Biochem Behav 47: 823-826.

File SE, Gonzalez LE, Andrews N (1996). Comparative study of preand postsynaptic 5-HT1A receptor modulation of anxiety in two ethological animal tests. J Neurosci 16: 4810-4815.

Follesa P, Cagetti E, Mancuso L, Biggio F, Manca A, Maciocco E et al (2001). Increase in expression of the $\mathrm{GABA}_{\mathrm{A}}$ receptor $\alpha 4$ subunit gene induced by withdrawal of, but not by long-term treatment with, benzodiazepine full or partial agonists. Brain Res Mol Brain Res 92: 138-148.

Gray A, Allison C, Pratt JA (1999). A role for AMPA/kainate receptors in conditioned place preference induced by diazepam in the rat. Neurosci Lett 268: 127-130.

Griffiths RR, Weerts EM (1997). Benzodiazepine self-administration in humans and laboratory animals - implications for problems of long-term use and abuse. Psychopharmacology (Berl) 134: 1-37.

Hauber W, Andersen R (1993). The non-NMDA glutamate receptor antagonist GYKI 52466 counteracts locomotor stimulation and anticataleptic activity induced by the NMDA antagonist dizocilpine. Naunyn Schmiedebergs Arch Pharmacol 348: 486-490.

Hayashi Y, Shi SH, Esteban JA, Piccini A, Poncer JC, Malinow R (2000). Driving AMPA receptors into synapses by LTP and CaMKII: requirement for GluR1 and PDZ domain interaction. Science 287: 2262-2267.

Izzo E, Auta J, Impagnatiello F, Pesold C, Guidotti A, Costa E (2001). Glutamic acid decarboxylase and glutamate receptor changes during tolerance and dependence to benzodiazepines. Proc Natl Acad Sci USA 98: 3483-3488.

Jackson A, Mead AN, Stephens DN (2000). Behavioural effects of $\alpha$-amino-3-hydroxy-5-methyl-4-isoxazolepropionate-receptor antagonists and their relevance to substance abuse. Pharmacol Ther 88: 59-76.

Jang CG, Oh S, Ho IK (1998). Changes in NMDAR2 subunit mRNA levels during pentobarbital tolerance/withdrawal in the rat brain: an in situ hybridization study. Neurochem Res 23: 1371-1377.

Karcz-Kubicha M, Liljequist S (1995). Evidence for an axiogenic action of AMPA receptor antagonists in the plus-maze. Eur $J$ Pharmacol 279: 171-177.

Lau CE, Falk JL, Dolan S, Tang M (1987). Simultaneous determination of lurazepam and five metabolites in serum by high-performance liquid chromatography and its application to pharmacokinetic studies in rats. J Chromatogr 423: 251-259.

Liao D, Hessler NA, Malinow R (1995). Activation of postsynaptically silent synapses during pairing-induced LTP in CA1 region of hippocampal slice. Nature 375: 400-404.

Liao D, Scannevin RH, Huganir R (2001). Activation of silent synapses by rapid activity-dependent synaptic recruitment of AMPA receptors. J Neurosci 21: 6008-6017.

Little HJ (1999). The contribution of electrophysiology to knowledge of the acute and chronic effects of ethanol. Pharmacol Ther 84: 333-353.

Lledo PM, Zhang X, Sudhof TC, Malenka RC, Nicoll RA (1998). Postsynaptic membrane fusion and long-term potentiation. Science 279: 399-403.

Matthews DB, Devaud LL, Fritschy JM, Sieghart W, Morrow AL (1998). Differential regulation of $\mathrm{GABA}_{\mathrm{A}}$ receptor gene expression by ethanol in the rat hippocampus versus cerebral cortex. J Neurochem 70: 1160-1166.

McNaughton N, Gray JA (2000). Anxiolytic action on the behavioural inhibition system implies multiple types of arousal contribute to anxiety. J Affect Disord 61: 161-176.

Menard J, Treit D (2000). Intra-septal infusions of excitatory amino acid receptor antagonists have differential effects in two animal models of anxiety. Behav Pharmacol 11: 99-108.

Menard J, Treit D (2001). The anxiolytic effects of intra-hippocampal midazolam are antagonized by intra-septal L-glutamate. Brain Res 888: 163-166.

Millan MJ (2003). The neurobiology and control of anxious states. Prog Neurobiol 70: 83-244.

Mohler H, Fritschy JM, Rudolph U (2002). A new benzodiazepine pharmacology. J Pharmacol Exp Ther 300: 2-8.

Molleman A, Little HJ (1995). Increases in non- $N$-methylD-aspartate glutamatergic transmission, but no change in gamma-aminobutyric acid B transmission, in CA1 neurons during withdrawal from in vivo chronic ethanol treatment. J Pharmacol Exp Ther 274: 1035-1041.

Nayak A, Zastrow DJ, Lickteig R, Zahniser NR, Browning MD (1998). Maintenance of late-phase LTP is accompanied by PKAdependent increase in AMPA receptor synthesis. Nature 394: 680-683.

Nestler EJ (2001a). Molecular basis of long-term plasticity underlying addiction. Nat Rev Neurosci 2: 119-128.

Nestler EJ (2001b). Neurobiology. Total recall - the memory of addiction. Science 292: 2266-2267.

Nestler EJ (2002). Common molecular and cellular substrates of addiction and memory. Neurobiol Learn Mem 78: 637-647.

Nusser Z, Sieghart W, Benke D, Fritschy JM, Somogyi P (1996). Differential synaptic localization of two major gamma-aminobutyric acid type A receptor alpha subunits on hippocampal pyramidal cells. Proc Natl Acad Sci USA 93: 11939-11944.

O’Brien RJ, Kamboj S, Ehlers MD, Rosen KR, Fischbach GD, Huganir RL (1998). Activity-dependent modulation of synaptic AMPA receptor accumulation. Neuron 21: 1067-1078. 
Oh S, Hoshi K, Ho IK (1997). Role of NMDA receptors in pentobarbital tolerance/dependence. Neurochem Res 22: 767-774.

Pellow S, Chopin P, File SE, Briley M (1985). Validation of open:closed arm entries in an elevated plus-maze as a measure of anxiety in the rat. J Neurosci Methods 14: 149-167.

Poisbeau P, Williams SR, Mody I (1997). Silent GABA A synapses during flurazepam withdrawal are region-specific in the hippocampal formation. J Neurosci 17: 3467-3475.

Rodgers RJ, Dalvi A (1997). Anxiety, defence and the elevated plusmaze. Neurosci Biobehav Rev 21: 801-810.

Salazar P, Tapia R, Rogawski MA (2003). Effects of neurosteroids on epileptiform activity induced by picrotoxin and 4-aminopyradine in the rat hippocampal slice. Epilepsy Res 55: 71-82.

Sanna E, Mostallino MC, Busonero F, Talani G, Tranquilli S, Mameli $\mathrm{M}$ et al (2003). Changes in $\mathrm{GABA}_{\mathrm{A}}$ receptor gene expression associated with selective alterations in receptor function and pharmacology after ethanol withdrawal. J Neurosci 23: 11711-11724.

Smith SS (2002). Withdrawal properties of a neuroactive steroid: implications for $\mathrm{GABA}_{\mathrm{A}}$ receptor gene regulation in the brain and anxiety behavior. Steroids 67: 519-528.

Song I, Huganir RL (2002). Regulation of AMPA receptors during synaptic plasticity. Trends Neurosci 25: 578.

Staley KJ, Soldo BL, Proctor WR (1995). Ionic mechanisms of neuronal excitation by inhibitory $\mathrm{GABA}_{\mathrm{A}}$ receptors. Science 269: 977-981.

Steppuhn KG, Turski L (1993). Diazepam dependence prevented by glutamate antagonists. Proc Natl Acad Sci USA 90: 6889-6893.

Tarnawa I, Vize ES (1998). 2,3-Benzodiazepine AMPA antagonists. Restor Neurol Neurosci 13: 41-57.

Tietz EI, Rosenberg HC, Chiu TH (1986). Autoradiographic localization of benzodiazepine receptor downregulation. J Pharmacol Exp Ther 236: 284-292.

Tietz EI, Zeng XJ, Chen S, Lilly SM, Rosenberg HC, Kometiani P (1999). Antagonist-induced reversal of functional and structural measures of hippocampal benzodiazepine tolerance. J Pharmacol Exp Ther 291: 932-942.
Trujillo KA, Akil H (1995). Excitatory amino acids and drugs of abuse: a role for $N$-methyl-D-aspartate receptors in drug tolerance, sensitization and physical dependence. Drug Alcohol Depend 38: 139-154.

Tsuda M, Suzuki T, Misawa M (1998). NMDA receptor antagonists potently suppress the spontaneous withdrawal signs induced by discontinuation of long-term diazepam treatment in Fischer 344 rats. Brain Res 790: 82-90.

Turrigiano GG (2000). AMPA receptors unbound: membrane cycling and synaptic plasticity. Neuron 26: 5-8.

Van Sickle B, Cox A, Schak K, John GL, Tietz E (2002). Chronic benzodiazepine administration alters hippocampal CA1 neuron excitability: NMDA receptor function and expression. Neuropharmacology 43: 595-606.

Van Sickle B, Tietz E (2002). Selective enhancement of AMPA receptor-mediated function in hippocampal CA1 neurons from chronic benzodiazepine-treated rats. Neuropharmacology 43: 11-27.

Xie XH, Tietz EI (1992). Reduction in potency of selective gammaaminobutyric acid A agonists and diazepam in CA1 region of in vitro hippocampal slices from chronic flurazepam-treated rats. J Pharmacol Exp Ther 262: 204-211.

Xie ZC, Buckner E, Commissaris RL (1995). Anticonflict effect of MK-801 in rats: time course and chronic treatment studies. Pharmacol Biochem Behav 51: 635-640.

Zamanillo D, Sprengel R, Hvalby O, Jensen V, Burnashev N, Rozov A et al (1999). Importance of AMPA receptors for hippocampal synaptic plasticity but not for spatial learning. Science 284: 1805-1811.

Zeng X, Xie XH, Tietz EI (1995). Reduction of GABA-mediated inhibitory postsynaptic potentials in hippocampal CA1 pyramidal neurons following oral flurazepam administration. Neuroscience 66: 87-99.

Zeng XJ, Tietz EI (1999). Benzodiazepine tolerance at GABAergic synapses on hippocampal CA1 pyramidal cells. Synapse 31: 263-277. 